\title{
ENSAIO BIBLIOGRÁFICO DISTANCIAMENTO, REFLEXIVIDADE E INTERIORIZAÇÃO DA PESSOA NO OCIDENTE
}

\author{
Luiz Fernando D. Duarte
}

\begin{abstract}
BOLTANSKI, Luc. 1993. La Souffrance à Distance. Morale Humanitaire, Médias et Politique. Paris: Éditions Métaillé. 288 pp.
\end{abstract}

1 Desde a publicação, em 1987, de Les Économies de la Grandeur (em colaboração com L. Thévenot), Luc Boltanski vem aportando sucessivas contribuições ao quadro analítico então inaugurado (Boltanski 1990; Boltanski e Thévenot 1989; 1991), que é, grosso modo, contemporâneo à implantação do novo laboratório que anima na École des Hautes Études en Sciences Sociales (o Grupo de Sociologia Política e Moral — GSPM). La Souffrance à Distance refina e ilumina aspectos relevantes da história do sujeito na ordem política da cultura ocidental moderna, de modo mais fluente e ameno que as obras anteriores, verdadeiros manifestos epistemológicos sustentados por uma arquitetura analítica de impecável rigor.

Esta nova obra reforça, sem dúvida, a impressão de novidade e riqueza que o esquema das "economias da grandeza política" veio aportar à sociologia contemporânea. A aplicação de uma rigorosa lógica empirista/nominalista aos problemas clássicos do vínculo sociopolítico, sem cair nas banalidades mais habituais do "individualismo metodológico", permite a Boltanski e seus companheiros de empreitada vigorosos recursos de análise de algumas áreas da vida social, sobretudo as que qualificam as sociedades modernas como "críticas" ou "reflexivas" (para usar dos seus termos).

Numerosos e importantes trabalhos surgiram assim à sombra do GSPM, dedicados à análise das formas de "protesto", "denúncia" e "justificação" ("provas", "acordos", "traduções", "transportes" etc.) nas mais variadas áreas da experiência social das sociedades metropolitanas (justamente aquelas onde prevalecem as equivalências políticas propícias à generalização de um universo "crítico") ${ }^{1}$.

Algumas estratégias analíticas dessa "sociologia da crítica" se afastam das práticas da sociologia européia e vêm ao encontro das da antropologia social que se desenvolve no Brasil: o pressuposto de equivalên- 
cia e continuidade simbólica entre dados etnográficos e históricos, por um lado, e entre fontes eruditas e comuns, de outro, e a disposição de privilégio ao discurso do informante (sua oportunidade, seu ritmo, sua lógica próprias) que ecoa, até certo ponto, os ditames do "seguir os atores" e "levá-los a sério" (cf., p. ex., Boltanski 1990:57; Boltanski e Thévenot 1991:25).

Em um outro nível, a produção do GSPM põe em evidência tensões também presentes hoje na nossa antropologia, como no tocante à recusa do que chamam de "sociologia crítica" (a que se opõe a sua "sociologia $d a$ crítica") e suas estratégias de desvendamento [dévoilement] e de suspeita [soupçon] em relação às experiências dos atores sociais e às fontes de sua lógica. O alvo central e mais explícito dessa recusa é a sociologia de Pierre Bourdieu e seu grupo, considerada desqualificadora dos sujeitos sociais por reduzi-los a fantoches de suas determinações sociológicas (no sentido de decorrentes de "posições" sociais cuja determinação subjacente cabe "desvendar").

O radical empirismo que justifica essa atitude de crítica aos "sociologismos" aparece também na denúncia da "sociologia dos valores", categoria pela qual designam todos os "culturalismos" "realistas" (maxime o estruturalismo lévi-straussiano). Essa posição se choca com muito do que se faz em antropologia hoje, mas certamente encontra eco nas correntes interpretativistas, hermenêuticas e pragmatistas contemporâneas.

Uma das implicações incômodas dessa atitude epistemológica para uma antropologia que permaneça universalista e comparativa é a do seu radical enraizamento na premissa individualizante da cultura ocidental moderna de abolir toda possibilidade de classificar de modo sistêmico as diferenças culturais ou societárias. Como a vida social passa a ser vista como uma justaposição de redes de negociação em torno de objetos apenas relativamente predeterminados (as pré-conventions) (cf.:85) e todo o interesse analítico se centra nas condições em que se dão esses enfrentamentos "críticos" ou "reflexivos" (condições de produção e troca de instrumentos e disputas discursivas), desaparece a possibilidade de levar a sério as grandes descontinuidades "culturais" 2 .

Isso implica uma relativa desqualificação das situações características das sociedades não metropolitanas (além, evidentemente, das não ocidentais), uma vez que essas sociedades devem ser vistas (se aplicarmos os requisitos do Grupo) como imperfeitamente ou incompletamente "críticas", com tensões decorrentes da própria difusão diferencial da generalização do vínculo típico da cité civique (a forma cabal das unida- 
des políticas que eu prefiro chamar de "individualistas"). É bem possível, aliás, que essa limitação pudesse ser levantada contra o horizonte analítico do Grupo em relação a muitas situações sociais presentes no próprio seio das sociedades metropolitanas ${ }^{3}$.

2. O encanto de La Souffrance à Distance reside em primeiro lugar no fato de que Boltanski se detém aí, justamente, em uma sutilíssima recuperação das condições de emergência da sociedade moderna (associável primordialmente, do meu ponto de vista, à sua cité civique), sob o ângulo da relação entre o público e o privado, entre o estatuto político dos vínculos sociais e as condições psicológicas dos sujeitos que os constituem: "retornar ao momento em que se apresentam na política — de maneira quase concomitante - o ideal do espaço público, como lugar transparente de uma conversação generalizada, e, por outro lado, a demanda por piedade, dedicando-nos particularmente a descrever a tensão suscitada pela aproximação dessas duas exigências" (:37). A "questão humanitária" a que se refere genericamente o prefácio abarca um complexo horizonte de formas sociais ligadas justamente à reestruturação dos vínculos que passam a configurar o universo "moderno".

Coerentemente com a posição empirista referida, não importa muito para o autor a maneira sistemática em que essas novas formas se distinguem das que as precederam na própria cultura ocidental e - muito menos - das suas alternativas contemporâneas em outras culturas. A figura da "piedade", que caracteriza originariamente o universo em questão, opõe-se a duas outras, consideradas explicitamente como "alternativas", mas apresentadas de alguma forma como "antecessoras": a "compaixão" e a "comunitariedade". Essas figuras têm, porém, um caráter não sistêmico em relação à piedade moderna e se mantêm como imagens liminares, periféricas ao universo da plenitude social.

A novidade da figura da "piedade" é a da distância que se interpõe necessariamente entre o sofredor e os que se dão conta de seu sofrimento. Nas duas outras tópicas uma relação direta unia esses dois atores, expostos à co-presença social. A "questão humanitária" moderna transporta o problema clássico do "bom samaritano" para um patamar diferente de engajamento e negociação. A sua transformação em uma "política" exige que o sofrimento seja tratado "à distância", pois ele visa a "generalização" (que ocupa o lugar da "universalização" no jargão empirista). Mas, ao mesmo tempo, não pode prescindir da referência e evocação do "sofrimento" efetivo — preferencialmente coletivo —, a partir do qual desenvolve sua panóplia discursiva e institucional. A tensão entre a 
abstração e a concretude dos dois movimentos está na raiz dos aspectos cruciais da experiência moderna sobre os quais se debruça a análise.

Boltanski associa explicitamente essa passagem a referências clássicas da emergência da modernidade contra o pano de fundo da "velha cultura européia" (como dizia Rousseau). A "política da piedade" evoca, assim, a preeminência das relações "generalizadas" sobre as relações "locais" (:18) (que correspondem à oposição sociológica entre "universalismo" e "particularismo"), a de um "universalismo abstrato" sobre um "comunitarismo estreito" (:8), a de uma "generalidade de ordem política" sobre uma "generalidade de ordem espiritual" (:21), e, enfim, a instauração mesma de nosso celebrado "espaço público": "a constituição de um espaço público é estreitamente solidária de uma definição da legitimidade que enfatiza a possibilidade de uma observação sem perspectiva particular" (:44).

Sobre esse pano de fundo, Boltanski desenvolve a segunda parte do livro, dedicada ao que chama de "as três tópicas do sofrimento": a "denúncia", o "sentimento" e a "estetização". Esmiuça aí as operações pelas quais se constroem os regimes de conversão ou "transporte" do reconhecimento ou observação empírica do sofrimento para o plano da generalidade "política", pela ação à distância que o enfrentamento com o fato do sofrimento impõe. Na verdade há um deslizamento entre o público e o privado ou entre o macro e o micropolítico da primeira tópica (produtora de formas políticas diretas cruciais para a história do Ocidente) para as últimas, mais indiretamente "políticas", porque preliminarmente comprometidas com o estatuto do sujeito moderno e sua interioridade (o autor cita com carinho, já na Introdução, a relação de sua problemática com a da "cultura da autenticidade" tratada no Sources of the Self, de Charles Taylor).

3. A principal figura da grande transformação analisada por Boltanski é a do "espectador", o sujeito dessa "observação sem perspectiva particular" que se institucionaliza no século XVIII, a partir da possibilidade conceitual e prática de tudo ver no mundo social e de ver sem ser visto (como na figura do "anonimato urbano" que aí desponta). O tema é declinado, inicialmente, a partir do riquíssimo imaginário do teatro no Século das Luzes, quando a ênfase metafórica se desloca da velha figura do mundo como palco (e de seus atores e máscaras) para a da contemplação, ao mesmo tempo engajada e distanciada, dos "espectadores" anônimos dispersos na platéia escura (que logo incluirá os "críticos"). É perseguido ainda nos outros novos recursos da comunicação que compõem justamen- 
te o alvorecer do espaço público: os cafés, as representações das artes figurativas e o jornalismo (de onde surge o mote explícito do título da famosa folha de Addison e Steele, fundada em 1709 e renomeada The Spectator em 1711). O autor procura desqualificar, explicitamente, a precedência dos modelos da ciência natural nesse desenvolvimento (:44), mas acaba reconhecendo que o próprio texto que utiliza como fio condutor de sua análise é escrito sob a inspiração dessa cosmologia "sem perspectiva particular" com que Newton armou o essencial das primeiras imagens do mundo individualista: "A Teoria dos Sentimentos Morais [de Adam Smith] visa transferir ao tratamento do problema moral o método utilizado por Newton no domínio da filosofia natural" (:59)

O universo social assim configurado é o que se qualifica pela "mobilidade", pela abertura do horizonte dos deslocamentos sociais, da "aquisição" de status, do predomínio da liberdade individual sobre os lugares tradicionalmente "atribuídos". Como diz o autor: "O espaço público supõe a constituição de um observador desprendido, desengajado, sem compromissos prévios e, sobretudo, sem vínculos locais, capaz de pairar sobre as singularidades da sociedade, da mesma maneira com que o geógrafo, o cartógrafo ou o pintor inspirados pelo ideal cartográfico pairam sobre as singularidades da paisagem" (:51).

Uma das implicações políticas mais imediatas desses novos valores é a da intervenção dos intelectuais tornados "críticos sociais", sobretudo por intermédio da figura dos "casos" (les affaires). Boltanski cita o papel precursor dos "casos" publicizados por Voltaire (o do Cavalheiro de La Barre e o da família Calas), pela via da análise com que Elisabeth Claverie nos brindou no Museu Nacional em 1990, hoje felizmente publicada (cf. Claverie 1993). O essencial desse mecanismo repousava na presunção ou demonstração - como o faz até hoje - do "não comprometimento prévio" do espectador, o que o autoriza a converter o caso local em uma questão pública e universal:

“[...] no ideal do espaço público um sofrimento local pode ser transportado sem deformação, de maneira a se tornar disponível para qualquer um, ou seja, para todos aqueles que - por força da disponibilidade que lhes confere sua ausência de comprometimento prévio - são livres para dele se apropriar, ao se descobrirem concernidos e passarem ao engajamento e à adoção da causa como sua" (:54).

Essa possibilidade e disposição de "imparcialidade" constitui o pano de fundo da institucionalidade pública moderna ${ }^{5}$, podendo ser 
aproximada tanto das análises de Habermas, Foucault e Latour, como o faz Boltanski, quanto das questões mais clássicas da "legitimidade burocrática" de Weber ou do "processo civilizatório" de Elias. O autor comenta como ela ainda se mantém decisiva para todo o universo das comunicações públicas e para a continuidade desse crucial ator político que então nascia: a "opinião pública". Suas referências às polêmicas contemporâneas a respeito da televisão prenunciam as que hoje se tornam endêmicas em torno das chamadas "redes eletrônicas" (que levam às últimas conseqüências a possibilidade do distanciamento, do tudo ver sem ser visto).

Boltanski credita a Adam Smith ter acrescentado ao tema geral do "espectador" o de sua "internalização": "the man within", "the man in the breast" ou "the internal voice" (:58). O espectador deve ser livre de toda amarra ou comprometimento "atribuído" ou a priori. Mas ele deve ser também dotado de uma disposição abstrata e universal de "simpatia" pelo sofrimento de seus semelhantes ${ }^{6}$. Boltanski lembra a proximidade, assim, de Adam Smith de Shaftesbury ou Hutcheson, contra os modelos "egoístas" de Hobbes e Mandeville ou o modelo "solipsista" de Locke. Também poderia tê-lo aproximado de Rousseau, atribuindo ao absolutamente autônomo homme naturel a famosa pitié originária.

O autor é muito claro sobre a indissociabilidade dessa representação do sujeito, da nova concepção de sociedade como uma "coleção de indivíduos separados", a que os modelos holistas (evocados nas figuras liminares da "identificação comunitária" ou da "fusão edênica") não podem mais servir de fundamento (:62-63). Qualquer motivação para a "relação social" deve agora provir da "natureza" dos indivíduos, de sua constituição individual. Assim a disposição da "simpatia". Assim a faculdade da "imaginação", pela qual "o espectador se dá a si mesmo a representação dos sentimentos e das sensações do sofredor" (:62) e o próprio "sofredor" também pode se imaginar na posição do "espectador". Estabelece-se, desse modo, a "simetrização" entre os agentes sociais, que garante, nos termos de Boltanski, a projeção política de uma "cité" harmoniosa. Em outros termos, poder-se-ia dizer que estavam dadas as bases de justificação do "individualismo quantitativo" simmeliano, garantindo a díade mínima dotada de liberdade e igualdade a fundar a nova societas. Em um belo desenvolvimento paralelo, o autor aporta a contribuição ao argumento da passagem dos "particulares" isolados para a "generalidade" propiciada pela obra de Adam Smith sobre as Considerações sobre a Origem e a Formação das Línguas. A análise original procurava mostrar como as palavras abstratas surgiam de designações particulares, concre- 
tas, detendo-se com preciosa exatidão sobre a palavra "eu", de cujas novas ressonâncias como valor universalizante resume as implicações: "ela reúne, em sua significação, as qualidades aparentemente contraditórias de uma individualidade precisa e de uma generalização muito ampla" (Smith apud:66).

O "espectador" que sustenta a sociedade "newtoniana" que então se passa a constituir e autojustificar não restringe porém sua atitude distanciada ao mundo público. Ele se volta sobre si mesmo, se desdobra em uma interioridade, usa sua "consciência" de forma crítica e reflexiva: "Quando examino minha própria conduta, quando quero julgá-la e procuro condená-la ou aprová-la, é evidente que eu me divido de alguma maneira em duas pessoas, e que o eu avaliador e juiz preenche um papel diferente do outro eu cuja conduta ele avalia e julga" (Smith apud:65). Boltanski não se interessa em articular o surgimento histórico dessa representação fundamental com as outras dimensões culturais de nossa Grande Transformação. A mais importante é, sem dúvida, a que retraça essa "reflexividade" ao núcleo simbólico da tradição cristã, com sua ênfase na relação "ética" da alma individual com a divindade, tão claramente enunciada em Santo Agostinho e tão nitidamente retomada na Reforma protestante. O tema da "conversão" interior implica o exame de consciência e a tomada de distância em relação a si mesmo - questões a que a figura do "re-nascimento" e a instituição do batismo tardio emprestaram formas institucionais recorrentes na modernidade (cf. Mauss 1973a; Dumont 1983; Duarte e Giumbelli 1994).

O desenvolvimento dos modelos "psicologizados" da Pessoa moderna deriva diretamente desse princípio cultural, seja na tradição da psiquiatria, desde o modelo "moral" do alienismo francês (elogiado por Hegel justamente por pressupor uma dinâmica interior, entre a parte sã e a parte alienada do espírito) até a elaboração do conceito de esquizofrenia, seja na tradição das investigações sobre o "inconsciente", das inquietações em torno da "sugestão" e da "hipnose" até a psicanálise freudiana (com sua radical objetivação da divisão interior).

O pensamento sociológico também soube enfatizar desde muito cedo a importância da reflexividade pela divisão interior: Mauss acrescentou ao Homo Duplex de Durkheim o homme divisé para lidar exatamente com a emergência histórica dessa forma específica de noção de Pessoa (cf. Mauss 1973b:306); Elias reagrupou as pistas de Simmel e as de Weber no tema do "autocontrole", do cortesão portador da máscara facial, justamente para enfatizar a crucialidade desse mecanismo no processo instituidor de nossa "civilização" (Elias 1973; 1974). 
Boltanski enfatiza, complementarmente à filosofia moral, os desenvolvimentos importantíssimos que essa "topografia da interioridade" obtém no mundo das formas literárias. O "ensaio", o "romance" e a "autobiografia" passam a reproduzir sistematicamente o efeito a que o autor chama, com felicidade, de "introspector", para enfatizar seu paralelismo e acréscimo com a figura do "espectador" (:70). Sua lembrança de Sterne serve inclusive para realçar o surgimento dos recursos estilísticos da "ironia" e do "humor", ferramentas essenciais ao novo distanciamento dos sujeitos e ao cultivo dos controles públicos e íntimos.

A individualização radical implicada nesse modelo sugere ao autor uma outra fórmula de grande habilidade para introduzir sua análise das formas práticas modernas de tradução política do reconhecimento do sofrimento alheio: "é à medida que todos, no estado original de separação em que os coloca o postulado do solipsismo, se encontram sob o olhar desse espectador imparcial interiorizado, que se pode operar uma coordenação dos modos de comprometimento e engajamento emocional" (:78). Enfatiza-se, assim, com justiça o caráter "aposteriorístico", "programático", "propagandístico" mesmo, dos modelos propostos ao mercado dos comportamentos nas sociedades modernas ${ }^{7}$. Boltanski utiliza as imagens da busca de "coordenação" entre os "horizontes de expectativa" de autores e leitores para tratar dessa "formação de sensibilidades comuns", que constitui, sem dúvida alguma, o horizonte da construção social da Pessoa na cultura ocidental moderna. Esse é o sentido em que se vai desenhar sua análise das citadas três "tópicas": "para descrever essas formas próprias à alimentação da imaginação e as pré-convenções que enquadram a coordenação emocional entre quem passa e quem recebe um sofrimento à distância, retomaremos aqui o velho termo de tópi$c a^{\prime \prime}$ (:85, ênfase no original).

Fica mais clara nessa transição entre as duas metades do livro a dimensão pragmatista do empirismo de Luc Boltanski: embora ele pareça aspirar a uma "articulação" entre "um enfoque de tom estrutural, comportando uma orientação histórica", e "um enfoque de inspiração pragmática", seu objetivo último fica definido como o do atingimento de uma "pragmática do espectador" (:86). Com isso ele se refere ao privilégio da idéia de uma "competência" que incorpore as dimensões "afetivas" ou "emocionais" às "cognitivas", e escape assim aos temidos modelos dos valores e sistemas de representação. Como é habitual nessa perspectiva epistemológica, a invocação da "afetividade", da "experiência" e do "fluxo/vida" (contra "cognição", "estrutura" e rigor mortis) aparece sob a forma de postulados originários e apriorísticos, apesar de sua óbvia con- 
textualidade histórica e cultural. Sua conjugada presença é característica do pensamento romântico desde finais do século XVIII, como sistemática reação às ambições do universalismo iluminista, e as versões imanentistas e "empíricas" que hoje tendem a prevalecer parecem herdeiras de cruzamentos originais com o empirismo (e o pragmatismo) que, desde meados do século XIX, constituem a aliança antiuniversalista a qual me parece útil hoje chamar de "empirismo romântico" (cf. Duarte 1995).

4. A primeira das tópicas é a da "denúncia", articulada sobre o regime da "indignação". Das três possibilidades de transporte público e generalizado da atitude de observação à distância do sofrimento alheio essa é a primeira, certamente porque é a que mais implicações institucionais teve sobre o destino da cultura ocidental moderna. Boltanski lhe associa, entre outras características importantes, a de ter sustentado a dinâmica entre "direita" e "esquerda" no espaço político moderno (:97), a partir da constituição de sofredores coletivos (o povo, a classe operária, a nação etc.), da "denúncia" política desse sofrimento e da identificação de "perseguidores" responsáveis (a burguesia, o capital financeiro, a plutocracia, o internacionalismo judaico etc.).

A tópica da "denúncia" enseja, desse modo, um deslocamento do sofrimento para a procura do "acusado", que se manifesta desde logo na constituição da já mencionada forma dos "casos" públicos, fundada na conjugação da "investigação" e da "publicidade". O desenvolvimento dessa análise acompanha os trabalhos anteriores de Boltanski (junto com L. Thévenot) sobre os regimes de "justificação" nas ações conflituosas dentro das sociedades ocidentais metropolitanas (sobretudo Boltanski e Thévenot 1991), assim como as análises históricas já citadas de Elisabeth Claverie. A dimensão de "investigação" (enquête) dos processos de "denúncia" leva quase diretamente à constituição dos saberes sociológicos (ou, pelo menos, da tradição dessa "sociologia crítica" , contra a qual trabalha o GSPM) através do transporte da acusação para "sistemas" ou "estruturas" (:113). O marxismo parece encarnar mais plenamente esse caminho, mas também as sociologias de Durkheim e de Bourdieu (além do precursor comum Rousseau).

O tema do distanciamento ganha aqui uma espessura diferente, de grande riqueza analítica:

"As pessoas individuais são [passam a ser, nessa perspectiva], com efeito, agentes que - um pouco à maneira do herói hegeliano - servem ao sistema, acreditando servir a fins que eles próprios definiram. Eles devem ser 
então desdobrados [dédoublés] — a mão direita ignorando o que faz a mão esquerda - por meio de um dispositivo interno que pode tomar diferentes formas: inconsciente, má-fé etc." (:114).

A "antropologia do desdobramento"8 que o autor descreve inclui a determinação das formas de "tomada de consciência", de "conscientização", necessárias para a superação da má-fé ou do ressentimento linear, por exemplo. Boltanski lida assim com uma das questões mais centrais e problemáticas das teorias da Pessoa no Ocidente, seja do ponto de vista psicológico, seja do ponto de vista político-ideológico — ou, melhor ainda, do ponto de vista da psicologia das atitudes político-ideológicas sempre implícita nos discursos da militância social ou da análise sociológica em sentido estrito. Sua perspectiva formal (ou "pragmática") atém-se à evocação do problema - já que se impõe justamente não historicizá-lo. Não deixa com isso, porém, de contribuir para sua melhor percepção, ao torná-lo visível sob um ângulo tão pouco usual na reflexão das ciências sociais. Quem conhece há mais tempo a obra de Luc Boltanski talvez se lembre de sua proposta sobre a "reflexividade" diferencial da "cultura somática" entre as classes sociais (Boltanski 1979) que critiquei em outro momento (cf. Duarte e Ropa 1985). Seria interessante rever como sua problemática de então - aparentemente tão afastada de La Souffrance à Distance - , de alguma forma, se reencena nessas novas e brilhantes páginas sobre "desdobramento de si", "reflexividade" e "consciência".

5. As duas últimas tópicas (do "sentimento" e da "estética") são peças brilhantes de análise do desenvolvimento das formas da Pessoa nas representações eruditas ou "dominantes" do Ocidente. Um fio muito delicado as amarra através das ambigüidades do "transporte" "sentimental" do sofrimento para o mundo público.

A tópica do sentimento permite a Boltanski espraiar-se sobre o que chama de "metafísica da interioridade", que é na verdade uma nova versão, muito rica em informação bibliográfica, sobre o individualismo "qualitativo" no sentido de Simmel, "romântico" no sentido de Dumont ou "expressivo" no sentido de Charles Taylor. Nessa dimensão, marcada pelo processo da "sensibilização" (attendrissement) e pelo "acordo social" em torno da idéia de que há coincidência entre "interioridade" e "verdade" (:123), tudo opera sobre a prova do "coração". Desenvolve-se aí uma contribuição importante à complicada percepção social das "emoções". Boltanski resenha o que considera ser as duas tendências dessa sociologia (incluindo a psicologia social): a que se voltou para a demons- 
tração do caráter culturalmente construído das "emoções" (contra as reduções fisiológicas) e a que procurou — nos seus termos — "questionar o caráter espontâneo, não intencional e de certa forma gratuito, das emoções para privilegiar seus aspectos estratégicos" (:127). A recusa da redução analítica assim produzida é estratégica para a reapresentação dos postulados de seu antiuniversalismo: "o interacionismo semiológico, nesse sentido, não permite mais do que a fisiologia, de seguir [rester au plus près] a intuição das pessoas, procurando desdobrá-la em uma construção submetida a exigências de coerência interna, ou seja, de tratá-la em uma perspectiva antropológica" (:128). É uma das passagens mais claras do livro sobre a estratégia empirista do "accounting" que a escola toma da etnometodologia norte-americana.

Uma preciosa análise do que o autor chama de "a justificação política dos gostos singulares", em torno da obra de Sade, faz a mediação com a "tópica estética", assim definida: "ela consiste em não considerar o sofrimento do infeliz nem como injusto (para se indignar), nem como tocante (para se sensibilizar), mas como sublime" (:168, ênfases no original). Segue-se uma súmula precisa e inspirada da "subjetivação" romântica, que bem demonstra sua necessária articulação com os pressupostos de "interioridade", "reflexidade" e "distanciamento" esboçados no século XVIII sobre bases e com disposições, no entanto, tão diferentes. A estética do Mal, de Baudelaire a Nietzsche, nascida das injunções do transporte político do distanciamento em relação ao sofrimento alheio, acaba por implicar a rejeição radical de toda a política da piedade em que se desenrolaram as duas tópicas anteriores (:190) e, por isso mesmo, por se cantonar no universo da ficção.

A contribuição de Boltanski à compreensão da construção social da Pessoa na cultura ocidental moderna, aportada em La Souffrance à Distance, é sem dúvida uma das mais agudas disponíveis nos últimos tempos. Para todos, pois é difícil imaginar quem não admire a sintética grandeza desse trabalho. Para alguns, ele justificará linearmente a pertinência dos pressupostos epistemológicos sobre os quais se funda. Para outros, como eu, ele será mais um testemunho de que a riqueza do trabalho sociológico resulta de complexas tensões que operam um tanto à revelia das justificações ou racionalizações epistemológicas estritas em que nos escudamos. 
Luiz Fernando D. Duarte — Professor do Programa de Pós-Graduação em Antropologia Social (PPGAS) do Museu Nacional/UFRJ; Mestre e Doutor pela mesma instituição; autor, entre outros trabalhos sobre a construção da pessoa, as representações sobre os distúrbios mentais e a cultura das classes populares, de Da Vida Nervosa (Nas Classes Trabalhadoras Urbanas).

E-mail: lfdduarte@ax.ibase.org.br

\section{Notas}

1 Ver, por exemplo, Dodier (1993) e Chateauraynaud (1991), publicados na mesma "collection" dirigida por Boltanski nas Éditions Métailié, que inclui o La Souffrance à Distance.

2 O que está bem explícito na posição de Bruno Latour, um aliado importante do Grupo, contrário ao valor heurístico da dicotomia "tradicional" / "moderno" (cf. Latour 1983).

3 Seria curioso, por exemplo, reler o universo de "justificação" das redes de enfeitiçamento do Bocage francês estudadas por J. Favret-Saada (1977) à luz das fórmulas da sociologia boltanskiana, para julgar sua rentabilidade em uma situação limítrofe do universo "crítico".

4 Na verdade, a cosmologia paradoxal do "universo infinito" — "sem perspectiva particular" — vem de Galileu e Harvey, antes de Newton. Como diz Gusdorf (1974:83): “A mentalidade mecanicista implica um distanciamento [mise à distance] do universo: o espírito observa de longe a realidade material, doravante constituída como um campo epistemológico unitário".

5 Não é à toa que o nome de Imparcial foi tão comum para os primeiros periódicos modernos quanto os de Observador ou Espectador, e que a categoria para designar o profissional que produziria a comunicação dos fatos à distância viesse a ser a de um "relator": reporter (repórter).

6 Há alguns trabalhos importantes sobre a relação entre a filosofia moral e as teorias médicas e fisiológicas escocesas do século XVIII que confirmam minha hipótese de uma solidariedade fundamental entre a nova concepção "nervosa" do humano (que sustentava justamente, inclusive para Adam Smith, essa "simpatia") e a nova concepção individualista da sociedade (cf. Figlio 1975; Lawrence 1979; Duarte 1986). 
7 O que não deixa de lembrar a ênfase de Dumont no caráter "ideológico" do individualismo, complementar ou paralelamente ao seu caráter de "cosmologia".

8 Boltanski usa geralmente a categoria "antropologia" no sentido filosófico de uma teoria do homem e não no sentido mais habitual no Brasil de uma "antropologia social" ou "cultural".

\section{Referências bibliográficas}

BOLTANSKI, Luc. 1979. As Classes Sociais e o Corpo. Rio de Janeiro: Graal. 1990. L'Amour et la Justice Comme Compétences. Trois Essais de Sociologie de l'Action. Paris: Éditions Métailié.

e THÉVENOT, Laurent. 1987. Les Économies de la Grandeur. Paris: PUF.

e THÉVENOT, Laurent (orgs.). 1989. Justesse et Justice dans le Travail. Paris: PUF.

_ e THÉVENOT, Laurent. 1991. De la Justification. Les Economies de la Grandeur. Paris: Gallimard.

CHATEAURAYNAUD, Francis. 1991. La Faute Professionnelle (Une Sociologie des Conflits de Responsabilit). Paris: Éditions Métailié.

CLAVERIE, Elisabeth. 1993. "Sainte Indignation contre Indignation Éclairée. L'Affaire du Chevalier de La Barre". Ethnologie Française, XXII (3):271290.

DODIER, Nicolas. 1993. L'Expertise Médicale (Essai de Sociologie sur l'Exercice du Jugement). Paris: Éditions Métailié.

DUARTE, Luiz Fernando D. 1986. Da Vi- da Nervosa (Nas Classes Trabalhadoras Urbanas). Rio de Janeiro: Jorge Zahar Editor/CNPq. . 1995. "Formação e Ensino na Antropologia Social: Os Dilemas da Universalização Romântica". In: J. P. Oliveira Filho (org.), O Ensino da Antropologia no Brasil. Temas para uma Discussão. Rio de Janeiro: ABA. pp. 10-17.

e ROPA, Daniela. 1985. "Considerações Teóricas sobre a Questão do Atendimento Psicológico às Classes Trabalhadoras". In: S. Figueira (ed.), Cultura da Psicanálise. São Paulo: Brasiliense. pp. 178-201. e GIUMBELLI, Emerson. 1994. "As Concepções de Pessoa Cristã e Moderna: Paradoxos de uma Continuidade". Anuário Antropológico, 93: 77-111.

DUMONT, Louis. 1983. "De l'IndividuHors-du-Monde à l'Individu-dansle-Monde". In: Essais sur l'Individualisme. Paris: Seuil. pp. 33-67.

ELIAS, Norbert. 1973. La Civilisation des Moeurs. Paris: Calman-Lévy. 1974. La Société de Cour. Paris: Calman-Lévy. 
FAVRET-SAADA, Jeanne. 1977. Les Mots, la Mort, les Sorts. Paris: Gallimard.

FIGLIO, Karl M. 1975. "Theories of Perception and the Physiology of Mind in the Late Eighteenth Century". History of Science, 13:177-212.

GUSDORF, Georges. 1974. Introduction aux Sciences Humaines. Essai Critique sur Leurs Origines et leur Développement. Paris: Ophrys.

LATOUR, Bruno. 1983. "Comment Redistribuer Le Grand Partage". Revue de Synthése, IIIe. S. (110): 204-236.

LAWRENCE, C. J. 1979. "The Nervous System and Society in the Scottish Enlightenment". In: B. Barnes e S. Shapin (eds.), Natural Order. London: Sage Publications. pp. 19-40.

MAUSS, Marcel. 1973a. “Une Catégorie de l'Esprit Humain: La Notion de Personne, celle de 'Moi' ". In: Sociologie et Anthropologie. Paris: PUF. pp. 333-364.

. 1973b. "Rapports Réels et Pratiques de la Psychologie et de la Sociologie". In: Sociologie et Anthropologie. Paris: PUF. pp. 285-312. 